\title{
SPECTRAL DIFFERENCES OF TREE SPECIES BELONGING TO ATLANTIC FOREST OBTAINED FROM UAV HYPERSPECTRAL IMAGES
}

\author{
G. T. Miyoshi ${ }^{1, *}$ N. N. Imai ${ }^{1,2}$, A. M. G. Tommaselli ${ }^{1,2}$, E. Honkavaara ${ }^{3}$ \\ ${ }^{1}$ Graduate Program in Cartographic Sciences, São Paulo State University (UNESP), Presidente Prudente, SP 19060-900, Brazil; \\ (gabriela.t.miyoshi, nilton.imai, a.tommaselli)@unesp.br \\ 2 Dept. of Cartography, São Paulo State University (UNESP), Presidente Prudente, SP 19060-900, Brazil \\ ${ }^{3}$ Finnish Geospatial Research Institute, National Land Survey of Finland, Geodeetinrinne 2, 02430 Masala - eija.honkavaara@ nls.fi
}

KEY WORDS: Spectral difference, Tree species, Tropical Atlantic forest, Hyperspectral imagery, UAV, Wilcoxon-Mann-Whitney test

\begin{abstract}
:
The objective of this study is to evaluate the spectral difference between and within 11 tree species belonging to Brazilian Atlantic Forest located in the countryside of São Paulo State, Brazil. Tree species with different development stages may have different reflectance spectra because of the structural and phenological influence on it. Tree structure can affect the crown spectra due to the differences in geometry of view and density of shadow and sunlight pixels. Additionally, reflectance spectra can be similar between tree species belonging from different species, which affect the classification accuracy of these targets. In this sense, we evaluate the spectral difference between highly diverse Atlantic Forest using two different features extracted from individual tree crowns (ITCs). Mean reflectance spectra and mean normalized reflectance spectra of each ITC were used. They were computed from hyperspectral images acquired with sensor onboard unmanned aerial vehicle. Differences between tree species and within-species were calculated. Wilcoxon-Mann-Whitney test was applied in order to statistically evaluate whether the reflectance spectra were different. Results showed that the normalized values are more propense to increase the classification accuracies than using the mean values since it reduces the variability within-species and present a higher number of different values between-species.
\end{abstract}

\section{INTRODUCTION}

Tropical Atlantic forest is an interesting research topic because of its biodiversity wealth in contrast with its deforestation and degradation over the years (Myers et al., 2000). Most of the remnant of Brazilian Atlantic forest are fragmented (Ribeiro et al., 2009). Additionally, this type of forest protection and restoration is an important key to protect the ecosystem services (Rezende et al., 2018).

Hyperspectral data can provide detailed information about targets which are valuable to classification purposes. especially when working with targets like vegetation where the reflectance spectra can be similar (Price, 1994). Tree species reflectance is affected by a series of factors such as leaves disposal and shape, structure, soil reflectance and geometry of view (Asner, 1998). Thus, the same tree species can have different spectra depending on its stage of development and location, which can be a challenging factor when producing tree species maps.

Spectral difference among tree species was previously verified by Castro-Esau et al. (2006) and Ferreira et al. (2013) who found out that the spectral distance is higher between tree species than within-species, i.e., the spectral distance is higher for trees belonging to different species than for samples belonging to the same species. They evaluated the leaves reflectance spectra to contribute for monitoring efforts and biodiversity maintenance since the reflectance spectra influences the tree species classification (Castro-Esau et al., 2006; Ferreira et al., 2013).
Although Castro-Esau et al. (2006) also evaluated the tree crown spectra of five different tree species, they used a field spectroradiometer. When applied in image classification the acquisition of crown spectra is based on the pixel values. In this case, the geometry view needs to be mitigated since the crowns present different densities of shadows and sunlight depending of the tree structure. Moreover, the method to extract the crown spectra is equally important to classification purposes.

In this sense, the objective of this work is to evaluate the tree species variability among the samples belonging to the same class (within-species) and between-tree species. Spectral differences were calculated to two different features extracted from the individual tree crowns (ITCs), one corresponding to the mean spectra of each ITC and the other being the normalized spectra of each ITC. In addition, Wilcoxon-Mann-Whitney test was applied in order to verify statistically whether the spectra were different.

\section{MATERIALS AND METHODS}

\subsection{Tree species identified in field}

In this study, 11 tree species identified in field were studied. They belong to a submontane semideciduous seasonal forest located in Euclides da Cunha Paulista, countryside of São Paulo State, Brazil. A total of 101 tree spatial positions were identified in field. Their tree species were recognized by a professional who works in an arboretum with tree species of this type of forest. The tree species positions were collected inside a transect area with

Corresponding author 
approximate length and width of $500 \mathrm{~m}$ by $130 \mathrm{~m}$, respectively (Miyoshi et al., 2019). Trees from the transect area characterizes initial to advanced stage of ecological succession (Berveglieri et al., 2018).

Table 1 presents the number of trees identified in each group of tree species as well as its characteristics which are evergreen, semideciduous and deciduous. These characteristics and names were extracted from Lorenzi (1992a, 1992b, 1992c).

\begin{tabular}{|c|c|c|c|}
\hline Specie & Abbreviation & ITCs & Characteristics \\
\hline Astronium graveolens & $\mathrm{AG}$ & 4 & Deciduous \\
Apuleia leiocarpa & $\mathrm{AL}$ & 10 & Deciduous \\
Aspidosperma polyneuron & $\mathrm{AP}$ & 3 & Evergreen \\
Aspidosperma subincanum & $\mathrm{AS}$ & 4 & Deciduous \\
Copaifera langsdorffii & $\mathrm{CL}$ & 17 & Semideciduous \\
Endlicheria paniculata & $\mathrm{EP}$ & 7 & Evergreen \\
Helietta apiculata & $\mathrm{HA}$ & 10 & Evergreen \\
Hymenaea courbaril & $\mathrm{HC}$ & 11 & Semideciduous \\
Inga vera & $\mathrm{IV}$ & 8 & Semideciduous \\
Pterodon pubescens & $\mathrm{PP}$ & 7 & Deciduous \\
Syagrus romanzoffiana & $\mathrm{SR}$ & 20 & Evergreen \\
\hline
\end{tabular}

Table 1. Tree species and its number of samples identified in the study area

\subsection{Hyperspectral imagery}

Spectral features were extracted from a dataset of hyperspectral images acquired in July $1^{\text {st }}, 2017$ previous used by Miyoshi et al. (2019). Images were acquired with the Rikola camera which is based on the Fabry-Pérot Interferometer (FPI). This camera can acquire up to 25 spectral bands in the visible to near-infrared range (500 $\mathrm{nm}$ to $900 \mathrm{~nm}$ ). Spectral bands were set up as shown in Table 2, which also present the full width half maximum (FWHM) of each band.

\begin{tabular}{|cc|cc|cc|}
\hline $\boldsymbol{\lambda}$ & FWHM & $\boldsymbol{\lambda}$ & FWHM & $\boldsymbol{\lambda}$ & FWHM \\
\hline 506.22 & 12.44 & 628.73 & 15.30 & 720.17 & 19.31 \\
519.94 & 17.38 & 650.96 & 14.44 & 729.57 & 19.01 \\
535.09 & 16.84 & 659.72 & 16.83 & 740.42 & 17.98 \\
550.39 & 16.53 & 669.75 & 19.80 & 750.16 & 17.97 \\
565.10 & 17.26 & 679.84 & 20.45 & 769.89 & 18.72 \\
580.16 & 15.95 & 690.28 & 18.87 & 780.49 & 17.36 \\
591.90 & 16.61 & 700.28 & 18.94 & 790.30 & 17.39 \\
609.00 & 15.08 & 710.06 & 19.70 & 819.66 & 17.84 \\
620.22 & 16.26 & & & & \\
\hline
\end{tabular}

Table 2. Spectral setting of the FPI camera used to acquire the images use in this study.

The camera was onboard the custom UX4 UAV and the flight height was set up to $160 \mathrm{~m}$ above ground; UAV speed was setup to $4 \mathrm{~m} / \mathrm{s}$. One hyperspectral image was acquired ever two seconds providing forward overlap higher than $70 \%$ and side overlap of approximately $50 \%$.
Steps to acquire the orthomosaic of hyperspectral images included the geometric and radiometric processing described in Honkavaara et al. $(2013,2017)$ and Miyoshi et al. $(2018,2019)$ and can be summarized as:

1. Radiometric and laboratory corrections.

2. Exterior orientation parameters (EOPs) and interior orientation parameters (IOPs) determination.

3. Radiometric block adjustment and orthomosaics generation.

4. Pixels representing the digital numbers (DNs) transformed to reflectance factor values.

These four steps were performed using the Hyperspectral imager software (version 1.1) (Senop Ltd.,Oulu, Finland), the radBA software developed by the Finnish Geospatial Research Institute (Honkavaara et al., 2013), the Agisoft PhotoScan software (version 1.3) (AgiSoft, Saint Petersburg, Russia) and the ENVI software (version 3.1) (Exelis Visual Information Solutions, Boulder, Colorado). The final product was the hyperspectral orthomosaic with $10 \mathrm{~cm}$ of ground sample distance (GSD) with pixels in reflectance factor values.

\subsection{Spectral differences}

The method adopted to calculate the spectra differences were based on the distance from Price (1994) (Equation 1). Spectral differences within-species were calculated for all pairwise combinations, summarizing a total number of combinations as following (tree species/ number of combinations): Helietta apiculata (90); Endlicheria paniculata (21); Copaifera langsdorffii (136); Apuleia leiocarpa (45); Astronium graveolens (6); Aspidosperma subincanum (6); Inga vera (28); Hymenaea courbaril (55); Syagrus romanzoffiana (190); Aspidosperma polyneuron (3); Pterodon pubescens (21). To the betweenspecies spectral difference, a total of 55 pairwise combinations were calculated.

$$
D=\sqrt{\frac{1}{N-1} \sum_{i=1}^{N}\left[S_{1}\left(\lambda_{i}\right)-S_{2}\left(\lambda_{i}\right)\right]^{2}}
$$

where, $D$ is the spectral distance between spectra $S_{1}$ and $S_{2} ; N$ is the number of spectral bands and the index $i$ represents each spectral band where the difference will be calculated.

This difference is given by the root mean square difference between two spectra and averaged through the number of spectral bands since they are uniform distributed for all tested spectra (Price, 1994). Price (1994), who evaluated this metric for distinguished targets, found out that corn samples can have D values up to $7.56 \%$, which could be a potential problem to distinguish vegetation targets, such as sunflower and alfalfa. Castro-Esau et al. (2006) calculated D using different pairwise combinations including different sites and seasons. They observed that leaves from the same tree species may have different spectral characteristics due to its content.

Additionally, the Wilcoxon-Mann-Whitney test was applied to each pairwise combination between-species and for each spectral band with confidence level of $95 \%(\alpha=95 \%)$. This test is applied when there are not enough samples to affirm that they follow a normal distribution or even when the samples do not follow the normal distribution (Mann and Whitney, 1947; Nachar, 2008). It is a non-parametric test which verifies if two groups belong to the same population or not. The null hypothesis states that the two groups belong to the same population whereas the alternative hypothesis states that the groups belong to distinct populations. 
The hypothesis can be calculated by the medians of each group (Nachar, 2008):

$$
\begin{aligned}
& \mathrm{H}_{0}: \theta_{\mathrm{sp} 1}=\theta_{\mathrm{sp} 2}, \\
& \mathrm{H}_{1}: \theta_{\mathrm{sp} 1} \neq \theta_{\mathrm{sp} 2}
\end{aligned}
$$

where, $\theta$ is the median of each tree species to be compared sp1 and $\mathrm{sp} 2$ to each spectral band.

Considering 11 tree species, there are a total of 55 pairwise combinations for each spectral band, summing up a total of 1375 tests. This number of hypothesis tests was applied for the mean spectra, as well as for the mean normalized spectra, using the SciPy 1.1.0 package for Python (Virtanen et al., 2019).

The mean value was obtained by the arithmetic mean obtained from the pixels belonging to its respective polygon. Moreover, the mean normalized value was obtained by the arithmetic mean of normalized pixels, i.e., the pixel value of a band by the sum of this pixels in all spectral bands (Dalponte et al., 2019). The normalization tends to reduce the differences between the sunlit and shadowed pixels, assuming a uniformity distribution across the crown (Nevalainen et al., 2017; Dalponte et al., 2019; Yu et al., 1999). The normalization process was performed in order to reduce the spectra variability intra-samples belonging to the same tree species.

\section{RESULTS AND DISCUSSION}

Mean reflectance factor spectra of each tree species are given in Figure 1, where it is possible to see that the highest differences are in the red-edge region. However, visual confusion is noticed among Helietta apiculata, Inga vera, Hymenaea courbaril, Apuleia leiocarpa, and Aspidosperma subincanum even in the near-infrared region, which may affect these tree species classifications. In this region of the electromagnetic spectrum, the spectra are affected by the canopy structure since the leaves density and format influences the density of shadowed and sunlit pixels. In the visible part of the electromagnetic spectrum, visual similar response among all tree species are noticed. In this region, the vegetation spectra are mainly influenced by the pigment content of leaves, such as chlorophyll and carotenoids (Jensen, 2005).

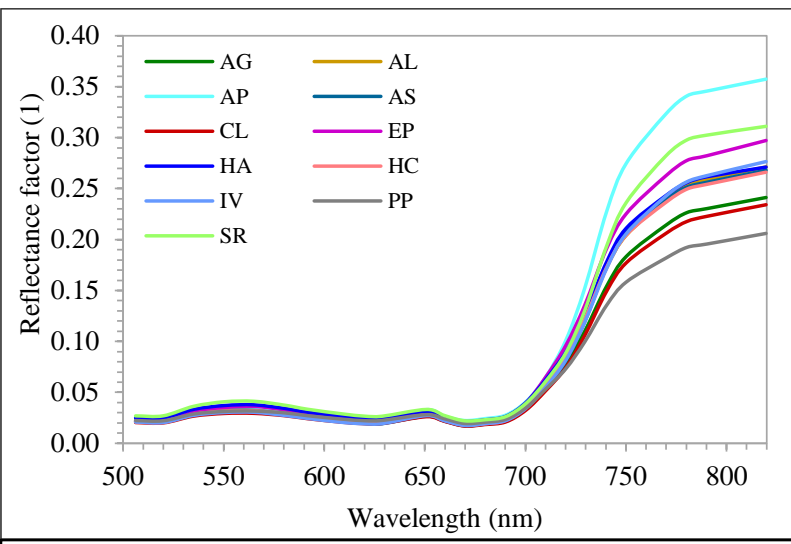

AL: Apuleia Leiocarpa; CL: Copaifera Langsdorffii; EP: Endlicheria Paniculata; HA: Helietta Apiculata; HC: Hymenaea Courbaril; IV: Inga Vera; PP: Pterodon Pubescens; SR: Syagrus Romanzoffiana.

Figure 1. Mean spectra for each tree recognized in field. Mean spectra extracted from the hyperspectral data
Figure 2 presents the distance D for each pairwise combination between-species using the mean reflectance factor spectra. The highest differences are for Aspidosperma polyneuron to the other tree species which indicate that this tree species presents higher difference in amplitude when compared to the other tree species, specially from Pterodon pubescens where the difference was 0.0688. Considering the difference between Aspidosperma polyneuron with Aspidosperma subincanum, the spectral difference is 0.0410 showing that even belonging to the same genus, they are more spectrally different when comparing Aspidosperma polyneuron with Syagrus romanzoffiana, for example, where $\mathrm{D}=0.0215$.

The smallest differences were obtained to the Hymenaea courbaril with Apuleia leiocarpa and with Aspidosperma subincanum both with distance equal 0.0019. Although Apuleia leiocarpa and Aspidosperma subincanum are deciduous and Hymenaea courbaril is semideciduous, the season when the images were acquired may have influenced its spectra. It is important to highlight that the images were acquired in July $1^{\text {st }}$, 2017, dry season in São Paulo State, specially where the images were acquired. In addition, observing the results from Figure 2 and comparing with the mean spectra of each tree species from Figure 1 it is observed that these values of spectral differences are in accordance with the spectra noticed in Figure 1. As pointed out previously, there was a visual confusion between the spectra of these tree species.

In sequence, Apuleia leiocarpa with Aspidosperma subincanum $(\mathrm{D}=0.0023)$, Inga vera with Apuleia leiocarpa $(\mathrm{D}=0.0026)$ and, Inga vera with Aspidosperma subincanum ( $\mathrm{D}=0.0027)$. From these distances it is noticed the challenge when classifying the tree species since it is suggested that they have similar reflectance factor spectra. Moreover, it is observed that the smallest differences are mainly for Apuleia leiocarpa, Aspidosperma subincanum and Hymenaea courbaril. Even belonging to different botanical genus and families, with different leaves sizes and blossoming, their reflectance factor spectra is similar. Considering the hypothesis test, the results showed that 443 of 1375 tested pairwise combinations had p-value lower than 0.05 , being the null hypothesis rejected. In other words, $32 \%$ of the observations are likely to belong to different populations, i.e., spectrally different.

When using the mean normalized reflectance factor to calculate the spectral differences, distinct results are obtained. Spectral differences between-species using the mean values of the normalized pixel, varied from 0.004 to 0.0081 (Figure 3). Highest differences were for Pterodon pubescens to the other tree species. Indicating that this tree species is more likely to be not confused with the other tree species when performing a tree species classification using the normalized spectral response as feature.

The smallest D value was for the pairwise of Endlicheria paniculata with Hymenaea courbaril $(\mathrm{D}=0.0004)$. In fact, Hymenaea courbaril, together with Apuleia leiocarpa and Copaifera langsdorffii present the smaller values to the other tree species being possible to infer that confusion of these species can occur during a classification process when using the normalized spectra. Thus, it is observed that the different shadowed and sunlit pixels auxiliary to differ these tree species. Moreover, results from the hypothesis test indicates that $40 \%$ of the observations belongs to different population, i.e., 555 cases of the 1375 tests. 


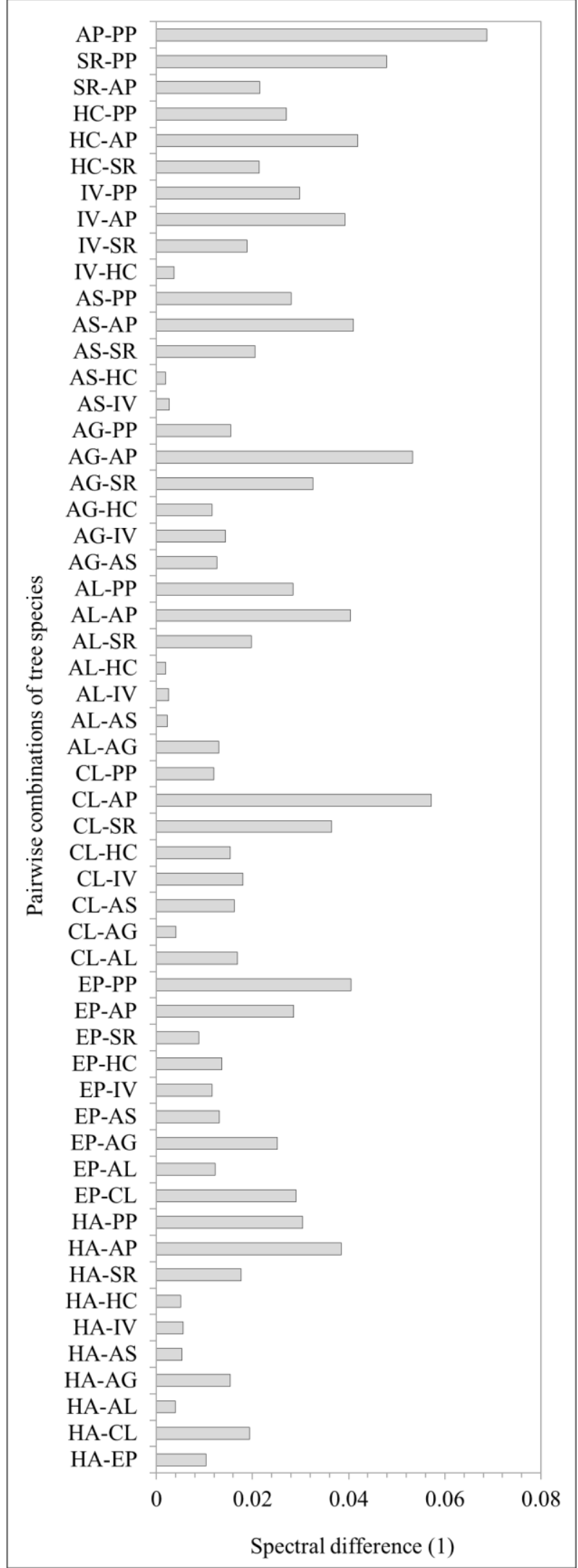

Figure 2. Spectral difference between the tree species - mean reflectance factor spectra. The $y$-axis represents the tree species pairwise combination

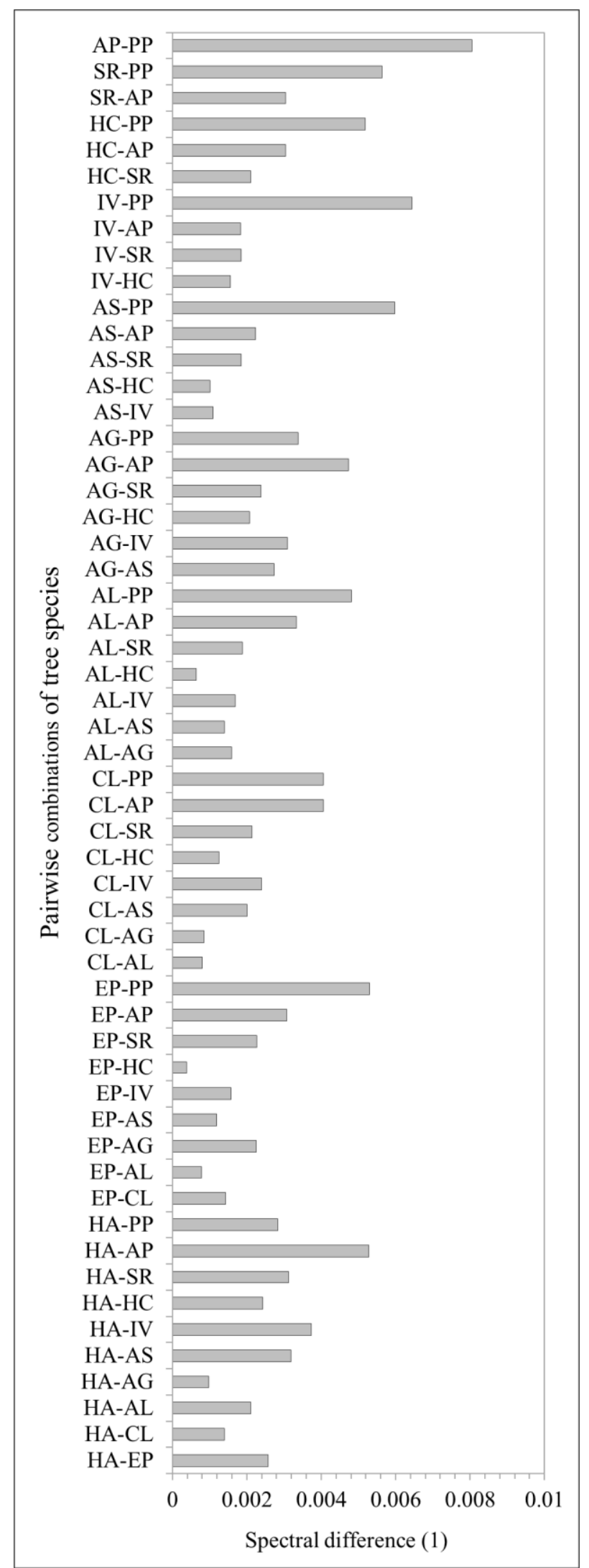

Figure 3. Spectral difference between the tree species - mean normalized features. The y-axis represents the tree species pairwise combination. 
Figure 4 presents the average spectral variability of each tree species considering the mean reflectance factor spectra and the mean normalized spectra and its standard deviation. As expected, the highest differences within-species are for the mean reflectance factor spectra, indicating that the spectral variability of reflectance factor intra species are higher using the mean spectra than using the normalized values. Before the normalization, the average spectral reflectance factor difference among the samples of Astronium graveolens was 0.0095. After the normalization, the value was reduced to 0.0007 less than twice of the original value. Even Aspidosperma polyneuron, which presented the smallest difference through the six pairwise combinations, the average difference was reduced from 0.0017 to 0.0008 .

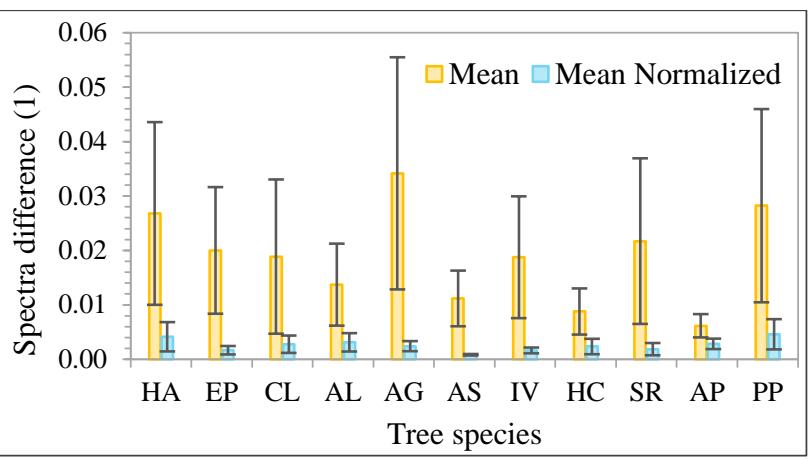

Figure 4. Spectra difference within-species considering the mean spectra and the mean normalized spectra for each sample

From results obtained using the mean normalized spectra (Figure 4) it is possible to see that the within-species differences presented lower values as well as degrees of variation. Thus, can be suggested that the use of normalized spectra decreases the variability from samples belonging to the same class. Differences in crowns illuminations caused by the acquisition's geometry and trees structure are reduced when using the normalized values and could improve the classifier performance.

There were no values higher than 0.0046 for the differences within-species belonging to the same class when considering the normalized spectra. The smallest value is no longer for Aspidosperma polyneuron, but for Aspidosperma subincanum (0.0008). Indeed, the magnitude of spectral differences has been completely changed. Inga vera was the fifth tree species with the smallest spectral difference within-species, but now it is the second one. Now, Helietta apiculata and Pterodon pubescens presented the higher differences with average spectral distances of 0.0041 and 0.0046 , respectively.

Comparing the results from Figure 2 and Figure 3 with Figure 4 it is noticed that the difference within-species in some cases are higher than the difference between-species as for Helietta apiculata. In this example, the difference within-Helietta apiculata samples was 0.0268 when using the non-normalized reflectance factor spectra. Pairwise combinations of Helietta apiculata with the other tree species, with exception of Pterodon pubescens and Aspidosperma polyneuron, presented smaller differences than its within spectra, i.e., lower than 0.0268 . Similar analysis is observed for Syagrus romanzoffiana, where the variability among the samples of its species is only lower than the difference of Syagrus romanzoffiana with Pterodon pubescens, Astronium graveolens and Copaifera langsdorffii.

From the experiments performed, it can be noticed that the high spectral variability within-tree species can be a challenge to classify the tree species. Possible reasons for these results are related with the different development stages of the study area, since the tree reflectance spectra change according to its age, development stage and environment (Buddenbaum et al. 2005).

Despite of the use of leaves from trees belonging to the Amazon forest in different ages, Chavana-Bryant et al. (2017) found out that the leaves' spectra were different, supporting our hypothesis about the within-species variability. Castro-Esau et al. (2006) and Ferreira et al. (2013) also evaluated leaves spectra, being observed similar results with our findings, i.e., there is a higher variability between species than within-species. In regard to our study area, it is noted that deciduous trees commonly have an irregular crown shape, which makes the reflectance pattern of tree species more difficult to be recognized (Ke and Quackebush, 2011). Moreover, lower trees can have their spectra affected by neighbourhood trees as well as the density of sunlit and shadowed pixels.

Finally, considering just the hypothesis tests, it is noticed confusion among the observations however, the mean normalized spectra present lower confusion, being recommend to be used in classification purposes. Nevalainen et al (2017) and Dalponte et al. (2019) successfully showed the use of normalized spectral features to tree species classification of Finnish forest and of United States of America forest, which characteristics differ from the Brazilian Atlantic forest.

\section{CONCLUSIONS}

The objective of this study was to evaluate the spectral separability between-species and within-trees belonging to the same class using the mean reflectance factor spectra and the mean normalize spectra obtained from hyperspectral imagery acquired with sensor onboard UAV. Hyperspectral images were acquired over highly diverse Brazilian Atlantic forest and after the geometric and radiometric processing, the mean values of manually delimited polygons were obtained and compared.

Even most part of the features showed to be statistically similar, the hypothesis test results showed that a higher number of null hypothesis were rejecting when using the normalized values. In this sense, the use of this type of feature is highly recommended to tree species classification.

\section{ACKNOWLEDGEMENTS}

The authors would like to acknowledge the funding provided by different institutions. This study was financed in part by the Coordenação de Aperfeiçoamento de Pessoal de Nível Superior - Brasil (CAPES) - Finance Code 001 (process number $88881.187406 / 2018-01$ ), in part by National Council for Scientific and Technological Development (CNPq), grant number 153854/2016-2, in part by São Paulo Research Foundation (FAPESP), grant number 2013/50426-4 and in part by Academy of Finland, grant number 305994.

\section{REFERENCES}

Asner, G. P., 1998. Biophysical and biochemical sources of variability in canopy reflectance. Remote sensing of Environment, 64(3), 234-253.

Berveglieri, A., Imai, N. N., Tommaselli, A. M., Casagrande, B., Honkavaara, E., 2018. Successional stages and their evolution in 
tropical forests using multi-temporal photogrammetric surface models and superpixels. ISPRS Journal of Photogrammetry and Remote Sensing, $\quad$ 146, 548-558. https://doi.org/10.1016/j.isprsjprs.2018.11.002.

Buddenbaum, H., Schlerf, M., Hill, J., 2005. Classification of coniferous tree species and age classes using hyperspectral data and geostatistical methods. International Journal of Remote Sensing, 26(24), 5453-5465.

Castro-Esau, K. L., Sánchez-Azofeifa, G. A., Rivard, B., Wright, S. J., Quesada, M., 2006. Variability in leaf optical properties of Mesoamerican trees and the potential for species classification. American Journal of Botany, 93(4), 517-530.

Chavana-Bryant, C., Malhi, Y., Wu, J., Asner, G. P., Anastasiou, A., Enquist, B. J., Caravasi, E. G. C., Doughty, C. E., Saleska, S. R., Martin, R. E., Gerard, F. F., 2017. Leaf aging of Amazonian canopy trees as revealed by spectral and physiochemical measurements. New Phytologist, 214(3), 1049-1063.

Dalponte, M., Frizzera, L., Gianelle, D., 2019. Individual tree crown delineation and tree species classification with hyperspectral and LiDAR data. PeerJ, 6, e6227. https://doi.org/10.7717/peerj.6227.

Ferreira, M. P., Grondona, A. E., Rolim, S. B., Shimabukuro, Y. E., 2013. Spectral variability of atlantic forest species. In 2013 IEEE International Geoscience and Remote Sensing SymposiumIGARSS, 2756-2758.

Honkavaara, E., Rosnell, T., Oliveira, R., Tommaselli, A., 2017. Band registration of tuneable frame format hyperspectral UAV imagers in complex scenes. ISPRS Journal of Photogrammetry and Remote Sensing, 134, 96-109. doi.org/10.1016/j.isprsjprs.2017.10.014.

Honkavaara, E., Saari, H., Kaivosoja, J., Pölönen, I., Hakala, T., Litkey, P., Mäkynen, J., Pesonen, L., 2013. Processing and assessment of spectrometric, stereoscopic imagery collected using a lightweight UAV spectral camera for precision agriculture. Remote Sensing, 5(10), 5006-5039. doi.org/10.3390/rs5105006.

Jensen, J. R., 2000. Remote sensing of the environment: an earth resource perspective. Upper Saddle River, N.J.: Prentice Hall.

Ke, Y., Quackenbush, L. J., 2011. A review of methods for automatic individual tree-crown detection and delineation from passive remote sensing. International Journal of Remote Sensing, 32(17), 4725-4747.

Lorenzi, H., 1992a. Árvores Brasileiras, vol. 1, ed 1. Plantarum, Nova Odessa

Lorenzi, H., 1992b. Árvores Brasileiras, vol. 1, ed 5. Plantarum, Nova Odessa.

Lorenzi, H., 1992c. Árvores Brasileiras, vol. 2, ed 1. Plantarum, Nova Odessa.

Mann, H. B., \& Whitney, D. R., 1947. On a test of whether one of two random variables is stochastically larger than the other. The annals of mathematical statistics, 50-60.

Miyoshi, G. T., Imai, N. N., Tommaselli, A. M. G., Honkavaara, E., 2019. Comparison of pixel and region-based approaches for tree species mapping in atlantic forest using hyperspectral images acquired by UAV. International Archives of the Photogrammetry, Remote Sensing and Spatial Information Sciences, 42(2/W13).

Miyoshi, G. T., Imai, N. N., Tommaselli, A. M. G., Honkavaara, E., Näsi, R., Moriya, É. A. S., 2018. Radiometric block adjustment of hyperspectral image blocks in the Brazilian environment. International journal of Remote Sensing, 39(1516), 4910-4930.

Myers, N., Mittermeier, R.A., Mittermeier, C.G., Fonseca, G.A.B., Kent, J., 2000. Biodiversity hotspots for conservation priorities. Nature 403, 852-858.

Nachar, N., 2008. The Mann-Whitney U: A test for assessing whether two independent samples come from the same distribution. Tutorials in quantitative Methods for Psychology, $4(1), 13-20$.

Nevalainen, O., Honkavaara, E., Tuominen, S., Viljanen, N., Hakala, T., Yu, X., Hyyppä, J., Saari, H., Pölönen, I., Imai, N. N., Tommaselli, A. M., 2017. Individual tree detection and classification with UAV-based photogrammetric point clouds and hyperspectral imaging. Remote Sensing, 9(3), 185. doi.org/10.3390/rs9030185.

Pricce, J. C., 1994. How unique are spectral signatures? Remote Sensing of Environment, v. 49, n. 3, 181-186.

Virtanen, P., Gommers, R., Oliphant, T. E., Haberland, M., Reddy, T., Cournapeau, D., Burovski, E., Peterson, P., ..., van der Walt, S. J., 2019. SciPy 1.0--Fundamental Algorithms for Scientific Computing in Python. arXiv preprint arXiv:1907.10121.

Yu, B., Ostland, M., Gong, P., Pu, R., 1999. Penalized discriminant analysis of in situ hyperspectral data for conifer species recognition. IEEE transactions on Geoscience and Remote Sensing, 37(5), 2569-2577. 